\title{
Lipsosomal amphotericin B: a review of its properties, function, and use for treatment of cutaneous leishmaniasis
}

This article was published in the following Dove Press journal:

Research and Reports in Tropical Medicine

\author{
Mohammad Reza Shirzadi ${ }^{1,2}$ \\ 'Center for Communicable Diseases \\ Control, Ministry of Health and Medical \\ Education, Tehran, Iran; ${ }^{2}$ Center for \\ Research of Endemic Parasites of Iran \\ (CREPI), Tehran University of Medical \\ Science, Tehran, Iran
}

\begin{abstract}
The genus Leishmania includes a number of protozoan parasites that cause a wide range of infections named leishmaniasis. Leishmaniasis may be appear in three clinical forms - cutaneous (CL), visceral, and mucocutaneous (MCL) - with variation in their presentation and severity: diffuse CL and post-kala-azar dermal leishmaniasis). The prevalent signs of $\mathrm{CL}$ are nonhealing ulcers on exposed skin, but infected patients may have other dermatologic symptoms. In the 1960s, amphotericin B deoxycholate was introduced as a second-line therapy for CL and MCL. However, widespread administration of the agent was prevented, due to its renal and systemic toxicity, high price, and obstacles to intravenous use in leishmaniasis-endemic regions. Amphotericin B binds to ergosterol in the photogenic cell membranes and causes changes in membrane permeability, leakage of ions, and finally cell death. Compared to amphotericin B deoxycholate, a higher dose of liposomal amphotericin B should be administered to show the treatment effect. A high percentage of liposomal amphotericin B is "fastened" in the liposome and not biologically effective. Amphotericin $\mathrm{B}$ deoxycholate has some toxic effects, and liposomal amphotericin B is meaningfully less toxic compared to it. Treatment options for $\mathrm{CL}$ are limited, due to variation in species causing CL and pharmacokinetic issues. Amphotericin B is effective against some particular forms of CL.
\end{abstract}

Keywords: liposomal amphotericin B, cutaneous leishmaniasis, Leishmania

\section{Introduction}

The genus Leishmania includes a number of protozoan parasites that cause a wide range of infections named leishmaniasis. Three clinical forms of leishmaniasis are cutaneous (CL), visceral (VL), and mucocutaneous, with variation in their presentation and severity: diffuse CL and post-kala-azar dermal leishmaniasis. In the Old World, majority of CL cases were caused by L. major or L. tropica but these are not the only Leishmaniaspp. that cause these diseases. L. donovani (post-kala-azar dermal leishmaniasis), L. aethiopica (diffuse CL), and other Leishmania spp. are also responsible for CL. In the New World, CL is caused by a large variety of species (at least eleven) with some (three) causing mucocutaneous infections. ${ }^{1,2}$

There are a number of available chemotherapeutic protocols to treat leishmaniasis, including pentavalent antimonials, paromomycin, pentamidine, miltefosine, amphotericin B deoxycholate, and liposomal amphotericin B. ${ }^{3}$ Increasing levels of resistance against antimonials and potentially miltefosine is an important drawback in the treatment of leishmaniasis. Existing treatment alternatives are restricted in
Shirzadi

Center for Communicable Diseases Control, Ministry of Health and Medical Education, Eyvanak St. Shahrak Gharb Tehran, Iran

Tel +98 9121455413

Tel +98912 I455413

Email shirzadim@gmail.com 
some patients, such as children with leishmaniasis and HIV patients coinfected with leishmaniasis. Liposomal amphotericin B has been shown to be useful in the treatment of leishmaniasis. ${ }^{3}$

Amphotericin B deoxycholate has been administered as a second-line therapy for the treatment of CL and mucosal leishmaniasis since the 1960s. Amphotericin B is a polyene macrocyclic antifungal molecule generated by Streptomyces nodosus. ${ }^{4,5}$ Widespread administration of the agent has been prevented, due to its renal and systemic toxicity, price, and obstacles to intravenous use in leishmaniasis-endemic regions. ${ }^{1}$

Lipid-supplemented derivatives of amphotericin B have been introduced to reduce renal toxicity of the drug and enable more extensive administration. Liposomal amphotericin B, amphotericin B incorporated into a bilayer liposome, is an approved lipid formulation of amphotericin B to treat a wide spectrum of infections (eg, leishmaniasis). ${ }^{6}$ In 1997, liposomal amphotericin B was introduced to maintain the antifungal action and reduce the toxicity of amphotericin $\mathrm{B} .{ }^{6,7}$

Amphotericin B, initially described as an alternative to stibnite for the treatment of mucocutaneous CL, has also been successfully used to treat severe VL and HIVLeishmania coinfection. ${ }^{8}$ Therapeutic failure or relapse after treatment has been reported, but is currently rare. ${ }^{9,10}$ Currently, amphotericin (especially in its liposomal form) is recommended by the World Health Organization and the main scientific societies as the firstline drug to treat any form of VL worldwide, not only severe or HIV-associated conditions but also in children and immunocompetent adults.

Liposomal amphotericin B (AmBisome; Astellus Pharma, Deerfield, IL, USA) was approved by the US Food and Drug Administration for treatment of VL at a dose of $3 \mathrm{mg} / \mathrm{kg} /$ day for seven doses (given on days $1-5,14$, and 21 ; total dose $21 \mathrm{mg} / \mathrm{kg}$ ). ${ }^{11}$ A number of physicians have reported success with administration of AmBisome as a highly tolerable drug for CL. ${ }^{12-15}$

\section{Mechanism of action}

The efficacy of AmBisomeis related to its ability to reach the site of infection. In in vivo preclinical model systems, the drug accumulates at sites or near fungal infections. Mechanistic studies disclosed that AmBisome binds to the fungal cell wall where amphotericin $\mathrm{B}$ is released from the liposome, traverses through the cell wall, and binds to ergosterol in the fungal cell membrane. ${ }^{16-18}$
As mentioned, amphotericin $\mathrm{B}$ acts through binding to ergosterol in the cell membranes. ${ }^{4,5}$ The binding may lead to changes in cell-membrane permeability, formation of pores, leakage of ions, induction of metabolic shock, and promoting cell death. ${ }^{4-6,19}$

Fluorescently labeled and gold-labeled liposomes (loaded with amphotericin B or blank liposomes) have been used in vitro and in vivo to illustrate the binding of liposomes to cell walls of the pathogens responsible for infection. $^{20,21}$ Empty liposomes (without amphotericin) remained intact and did not cause disruption in cells. However, the binding of liposomes loaded with amphotericin $\mathrm{B}$ led to cell death. ${ }^{20}$ This may have been due to disruption of liposomes and discharge of amphotericin $\mathrm{B}$ to bind to the ergosterol of the cell membrane and show antiparasitic activity. ${ }^{6}$

Amphotericin B can transfer from the liposome to the fungal or parasitic cell membranes, since its binding affinity to fungal or parasitic ergosterol is higher than cholesterol (main lipid part of the liposome). ${ }^{22}$

Transfer of amphotericin B from the liposome to the cell membrane happens most efficiently at body temperature. As such, temperature may be a significant factor that assists the transferal process. ${ }^{23}$

\section{Pharmacodynamics}

Compared to amphotericin B deoxycholate, a higher dose of liposomal amphotericin B should be administered to show a treatment effect. In vitro studies have shown that potent doses of liposomal amphotericin B and amphotericin B deoxycholate were 1.03 and $0.12 \mathrm{mg} / \mathrm{L}$, respectively, for $50 \%$ antipathogenic effect. These results indicate the differences of the two drugs in the term of the exposure-response relationship. ${ }^{6,21}$ Studies in animal models suggest that a high percentage of liposomal amphotericin B is "fastened" in the liposome and not biologically effective. ${ }^{24,25}$

\section{Pharmacokinetics of liposomal amphotericin B in humans}

Pharmacokinetic parameters of intravenous liposomal amphotericin B have been comprehensively described elsewhere, ${ }^{3,5,6,19,26,27}$ and are briefly reviewed here.

Pharmacokinetic characteristics of the medicine were first assessed based on its plasma concentrations in patients with febrile neutropenia. ${ }^{28}$ Over a dosage range of $1-7.5 \mathrm{mg} / \mathrm{kg} / \mathrm{day}$, the pharmacokinetics of the medicine 
were nonlinear. ${ }^{28}$ Compared to amphotericin $\mathrm{B}$ in the deoxycholate form, liposomal amphotericin $\mathrm{B}$ has a considerably dissimilar pharmacokinetic profile, and after single and multiple intravenous doses, the drug is distributed broadly and quickly. ${ }^{4,5}$ Within 4 days (after multiple doses of $1-7.5 \mathrm{mg} / \mathrm{kg} /$ day), amphotericin $\mathrm{B}$ reaches a steady-state plasma concentration more quickly than the deoxycholate formulation. ${ }^{4}$

Amphotericin B deoxycholate is highly bound to some plasma proteins, such as human serum albumin and $\alpha_{1}$ acid glycoprotein. ${ }^{29}$ In patient biopsies, the highest concentration of the drug is found in the liver and spleen, with moderate concentrations in the kidneys, lungs, myocardium and brain. ${ }^{30}$

The terminal half-life of liposomal amphotericin B in plasma is longer than other formulations (about 152 hours). ${ }^{27}$

Compared to amphotericin B deoxycholate, liposomal amphotericin B has a higher total plasma concentration. As mentioned earlier, a high percentage of circulating liposomal amphotericin $\mathrm{B}$ is probably inactive, since a high percentage of the drug is fastened in the liposome and not biologically effective. By direct contact with protozoan or fungal cell walls, the biologically active drug is released. ${ }^{27}$ The mechanism of amphotericin B metabolism is unknown. ${ }^{4}$

In the kidney, the largeness of the liposomes prevents glomerular filtration of the drug and drug interaction with distal tubuli cells. This results in reduced drug nephrotoxicity. ${ }^{4}$

At the end of the first week of administration, urinary clearance of liposomal amphotericin B is near $4.5 \%$ of the dose, which is meaningfully lower than for amphotericin B deoxycholate. Compared to amphotericin B deoxycholate, active excretion of liposomal amphotericin B into bile and clearance by feces occur to a minor extent. These findings suggest that liposomes around amphotericin B may prevent these clearance mechanisms from accessing the liposomally enclosed drug. ${ }^{27}$ Both amphotericin B deoxycholate and liposomal amphotericin B are excreted mainly as unaltered drugs through urinary and biliary excretion. ${ }^{31}$ Hepatic excretion of amphotericin B is moderate and not influenced by alterations in hepatic blood flow. Intact liposomes are not excreted into the urine and bile. ${ }^{27}$

\section{Toxicity}

Some toxic adverse effects are attributed to amphotericin $\mathrm{B}$ deoxycholate. However, liposomal amphotericin B has been showedn to be meaningfully less toxic compared to amphotericin B deoxycholate. ${ }^{32,33}$ Toxic effects of amphotericin B include nephrotoxicity and infusion-related toxicity.

Among commercially introduced lipid formulations of amphotericin B, liposomal amphotericin B has reliably the least nephrotoxicity. ${ }^{32,33}$ Low toxicity of liposomal amphotericin B may be due to the small number of preferential HDL receptors responsible for binding to the drug in the kidney. ${ }^{34,35}$ Renal toxicity is probably due to interaction of subcompartments of the kidney with free (diffusible) amphotericin B. The drug component of liposomal amphotericin B is enclosed in the liposome and not accessible for interaction with renal distal tubules. Large size of the liposomes prevents glomerulofiltration of the drug, and may explain the reduced renal toxicity of liposomal amphotericin B. ${ }^{36}$

The infusion of amphotericin B deoxycholate may result in the infusion-related toxicity that causes the acute fever and chills, likely because of proinflammatory cytokine reactions. $^{37}$

The infusion-related-toxicity of liposomal amphotericin $\mathrm{B}$ is reliably lower than amphotericin B deoxycholate and other amphotericin B-lipid complexes. ${ }^{38}$

Known adverse effects of liposomal amphotericin $\mathrm{B}$ areidiosyncratic, including flank/abdominal pain, chest pain/discomfort, and dyspnea that initiate in the first few minutes after infusion. With termination of the infusion and an antihistamine drug, these can be resolved. ${ }^{39}$ The clinical pattern of the infusion reaction is similar to liposome-linked drugs, and may be caused by liposomes, rather than the potent drug. The mechanism of such reaction is unknown, but assumed to be mediated by the complement system. ${ }^{40}$

In a study on the hepatotoxicity of liposomal amphotericin B, pediatric patients who received injectable liposomal amphotericin B were examined. ${ }^{41}$ During injection of the drug, mild-moderate increase in hepatic transaminases was observed in $59 \%$ of patients. After cessation of the treatment course, such increase was observed in one patient. ${ }^{41}$ Coadministration of liposomal amphotericin B with other hepatotoxic drugs may lead to abnormal liver function-test results in a dose-independent manner. ${ }^{42,43}$ The mechanism of liposomal amphotericin B hepatotoxicity remains unclear, and hepatic cells do not reveal any direct histopathological symptoms of toxicity. ${ }^{44}$

\section{Cutaneous leishmaniasis}

Phlebotomine sand flies are the vectors that transmit protozoan parasites to humans at the site of the bite. In the 


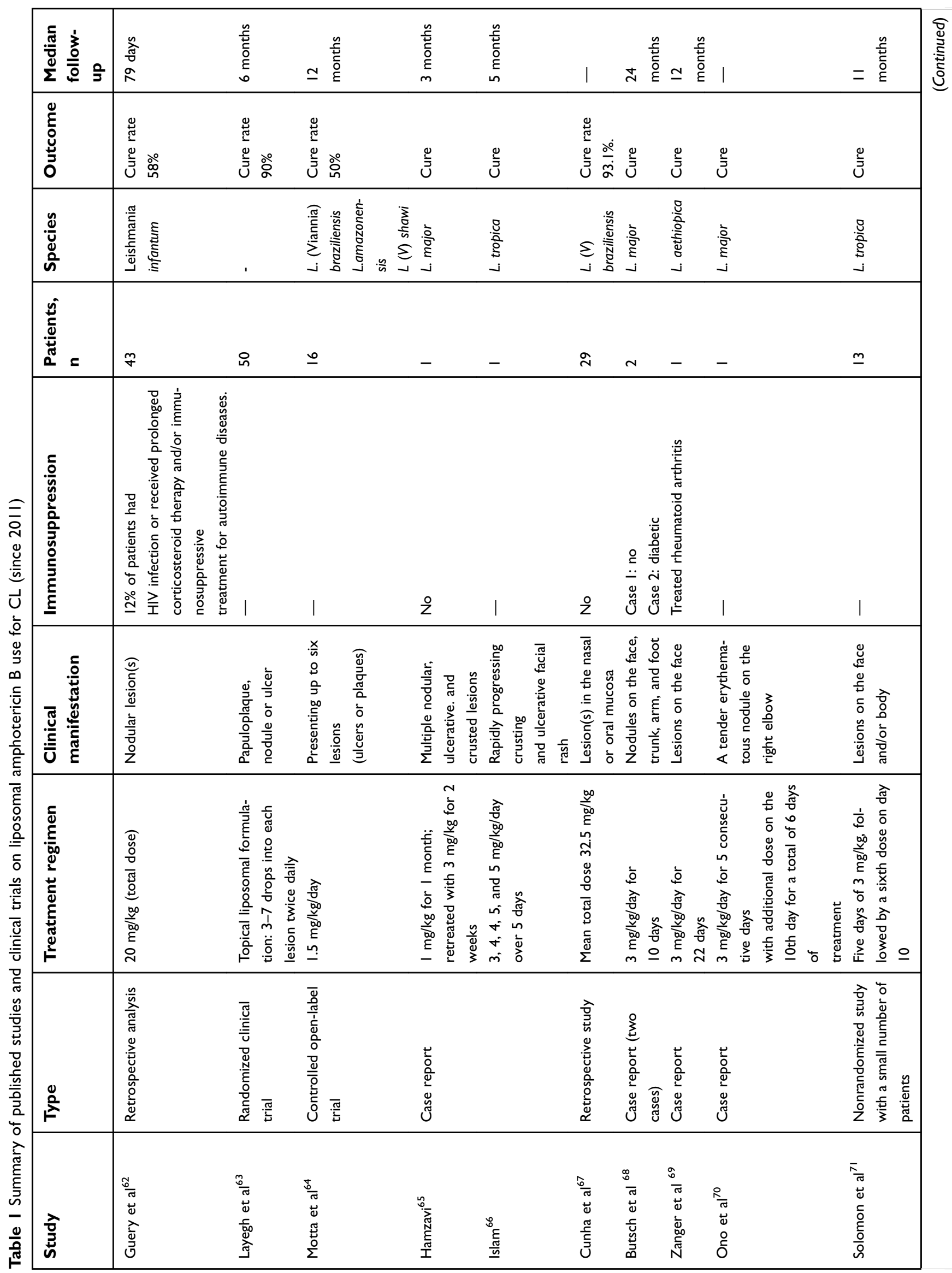




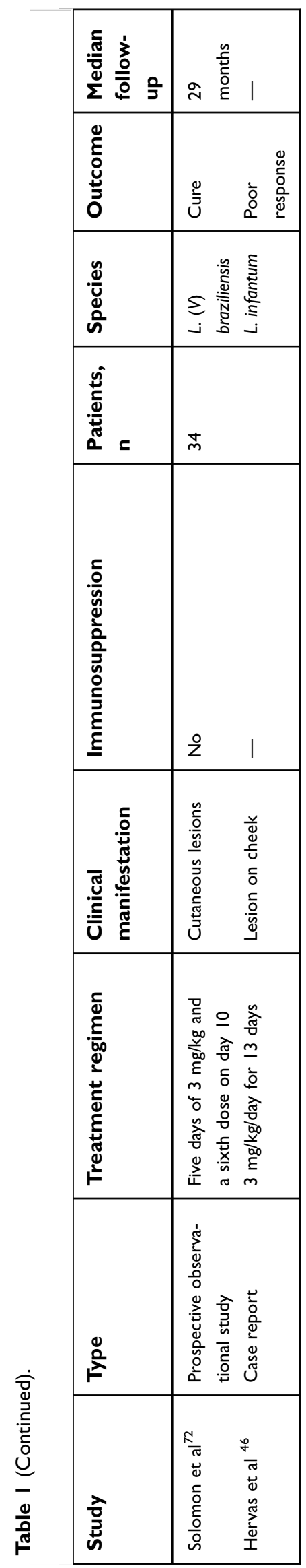

Old World, Leishmania major and L. tropica mainly cause $\mathrm{CL}$ and $L$. infantum and $L$. donovani cause the infection at lower frequences. In the New World, $L$. peruviana, $L$. guyanensis, $L$. braziliensis, or $L$. mexicana spp. mainly cause CL. ${ }^{45,46}$

Treatment options for CL are limited, due to the variation of species that cause it, as well as pharmacokinetic issues. $^{47,48}$ The efficiency of pentavalent antimonials against the various species of Leishmania is unknown. ${ }^{49}$ Amphotericin B and pentamidine are restricted to particular forms of CL. ${ }^{49}$ Different topical formulations of paromomycin have shown different clinical outcomes. ${ }^{50-53}$ The efficiency of oral miltefosine against CL is variable and species-dependent . 54,55 Liposomal amphotericin $\mathrm{B}$ has been shown to be useful in the treatment of CL. ${ }^{56}$

Some Old World trials showed that fluconazole and itraconazole (antifungal azoles) can be effective against L. major and L. tropica, respectively. ${ }^{57,58}$ A limited number of New World trials have shown that miltefosine, ketoconazole, and oral allopurinol may be effective for treatment of CL. ${ }^{59}$

Pentoxyphylline is an anti-inflammatory medicine that may be useful as adjunct therapy for $\mathrm{CL}^{48}$ Imiquimod (an antiviral TLR7 agonist) and immunomodulators (bacillus Calmette-Guérin and trehalose dimycolate) have been reported to act as other adjunct therapies. ${ }^{48,50,60,61}$

\section{Leishmaniasis coinfections}

Co-infections of Leishmaniaand HIV have been reported for CL and VL. Since the first illustrated case of HIV-VL coinfection in 1985, 35 countries have described such coinfections, with a growing number of cases in East Africa. In northeast Ethiopia, new cases are $23 \%$ of all VL patients. ${ }^{48}$

\section{Liposomal amphotericin B for treatment of $\mathrm{CL}$}

In recent years, successes with the usage of liposomal amphotericin B to treat CL have been described. Here, the literature describing the outcome of CL patients managed with liposomal amphotericin since 2011 was reviewed. Studies and clinical trials that reported the usage of liposomal amphotericin B for CL treatment before 2011 have been reviewed elsewhere. ${ }^{1}$

A summary of published studies and clinical trials (since 2011) on the use of liposomal amphotericin B to treat $\mathrm{CL}^{46,62-72}$ are shown in Table 1. Epidemiological and 
clinical data of Leishmania spp. and treatment results are included in Table1.

Most of the reports mentioned include a limited number of adults and children, individuals with immunosuppressive conditions, or people who had shown failure with early treatment by pentavalent antimony. The trials report drug effectiveness from just one geographic area or against just one species of Leishmania.

Considering Table 1, studies that involved patients infected with $L$. tropica showed positive outcomes. In the case of $L$. infantum, ${ }^{46,62}$ the infecting species may affect the effectiveness of liposomal amphotericin B, although age and existence of immunosuppressive conditions or comorbidities may also influence outcomes. ${ }^{46,62}$ Guery et al $^{62}$ showed a low cure rate for liposomal amphotericin B against L. infantum (Table 1). This may have been because the different populations investigatied included people visiting relatives and friends, emigrants, military individuals, and travelers. However, part of the low cure rate in that study may have arisen from repeated termination or alteration of the liposomal amphotericin B regimen. ${ }^{62}$

Motta et al tested a low-dosage amphotericin B regimen (1.5 mg/kg/day) against L. (Viannia) braziliensis, L. amazonensis, and L. (V) shawi. ${ }^{64}$ The cure rate of liposomal amphotericin B was low (50\%; Table 1). The authors suggested that a higher dose $(>1.5 \mathrm{mg} / \mathrm{kg} /$ day $)$ of the medicine is required to obtain better outcomes. ${ }^{64}$

\section{Disclosure}

The author reports no conflicts of interest in this work.

\section{References}

1. Wortmann G, Zapor M, Ressner R, et al. Lipsosomal amphotericin B for treatment of cutaneous leishmaniasis. Am J Trop Med Hyg. 2010;83(5):1028-1033. doi:10.4269/ajtmh.2010.10-0171

2. Magill A. Leishmania species: visceral (kala-azar), cutaneous, and mucosal leishmaniasis. In: Mandell GL, Bennett JE, Dolin R. editors. Principles and Practices of Infectious Diseases. Vol. 2, 7th. Philadelphia, PA: Churchill Livingstone Elsevier;2010:3463-3480

3. Kip AE, Schellens JH, Beijnen JH, Dorlo TP. Clinical pharmacokinetics of systemically administered antileishmanial drugs. Clin Pharmacokinet. 2018;57(2):151-176. doi:10.1007/s40262-017-0570-0

4. AmBisome (Liposomal Amphotericin B): Irish Summary of Product Characteristics. Foster City (CA): Gilead Sciences; 2007.

5. Coukell AJ, Brogden RN. Liposomal amphotericin B: therapeutic use in the management of fungal infections and visceral leishmaniasis. Drugs. 1998;55(4):585-612.

6. Stone NR, Bicanic T, Salim R, Hope W. Liposomal amphotericin

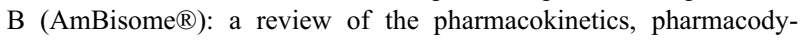
namics, clinical experience and future directions. Drugs. 2016;76 (4):485-500.
7. Wingard JR, White MH, Anaissie E, et al. A randomized, double-blind comparative trial evaluating the safety of liposomal amphotericin B versus amphotericin B lipid complex in the empirical treatment of febrile neutropenia. L Amph/ABLC collaborative study group. Clin Infect Dis. 2000;31(5):1155-1163.

8. Uliana SR, Trinconi CT, Coelho AC. Chemotherapy of leishmaniasis: present challenges. Parasitology. 2017;20:1-17.

9. Purkait B, Kumar A, Nandi N, et al. Mechanism of amphotericin $\mathrm{B}$ resistance in clinical isolates of Leishmania donovani. Antimicrob Agents Chemother. 2012;56(2):1031-1041.

10. Pandey A, Bansal V, Asthana AK, Trivedi V, Madan M, Das A. Maxillary osteomyelitis by mucormycosis: report of four cases. Int J Infect Dis. 2011;15(1):e66-e69. doi:10.1016/j.ijid.2010.09.003

11. Meyerhoff AUS. Food and drug administration approval of AmBisome (liposomal amphotericin B) for treatment of visceral leishmaniasis. Clin Infect Dis. 1999;28:42-48. doi:10.1086/515085

12. Amato VS, Rabello A, Rotondo-Silva A, et al. Successful treatment of cutaneous leishmaniasis with lipid formulations of amphotericin $\mathrm{B}$ in two immunocompromised patients. Acta Trop. 2004;92:127-132. doi:10.1016/j.actatropica.2004.06.006

13. Brown M, Noursadeghi M, Boyle J, Davidson RN. Successful liposomal amphotericin B treatment of Leishmania braziliensis cutaneous leishmaniasis. $\mathrm{Br} J$ Dermatol. 2005;153:203-205. doi:10.1111/ j.1365-2133.2005.06670.x

14. Rongioletti F, Cannata GE, Parodi A. Leishmaniasis due to L. infantum presenting as macrocheilitis and responding to liposomal amphotericin B. Eur J Dermatol. 2009;19:281-282.

15. Del Rosal T, Artigao FB, Miguel MJ, de Lucas R, Del Castillo F. Successful treatment of childhood cutaneous leishmaniasis with liposomal amphotericin B: report of two cases. $J$ Trop Pediatr. 2010;56:122-124. doi:10.1093/tropej/fmp073

16. Soo Hoo L. Fungal fatal attraction: a mechanistic review on targeting liposomal amphotericin B (AmBisome $(\mathbb{B})$ ) to the fungal membrane. J Liposome Res. 2017;27(3):180-185. doi:10.1080/ 08982104.2017.1360345

17. Palma E, Pasqua A, Gagliardi A, Britti D, Fresta M, Cosco D. Antileishmanial activity of amphotericin B-loaded-PLGA nanoparticles: an overview. Materials (Basel). 2018;11(7):pii: E1167. doi:10.3390/ma11081451

18. Grazziotin LR, Moreira LB, Ferreira MAP. Comparative effectiveness and safety between Amphotericin B lipid-formulations: a systematic review. Int J Technol Assess Health Care. 2018;34 (3):343-351. doi:10.1017/S026646231800034X

19. Moen MD, Lyseng-Williamson KA, Scott LJ. Liposomal amphotericin B: a review of its use as empirical therapy in febrile neutropenia and in the treatment of invasive fungal infections. Drugs. 2009;69 (3):361-392.

20. Adler-Moore J. AmBisome targeting to fungal infections. Bone Marrow Transplant. 1994;14(Suppl 5):S3-S7.

21. Lestner JM, Howard SJ, Goodwin J, et al. Pharmacokinetics and pharmacodynamics of amphotericin B deoxycholate, liposomal amphotericin B, and amphotericin B lipid complex in an in vitro model of invasive pulmonary aspergillosis. Antimicrob Agents Chemother. 2010;54(8):3432-3441.

22. Readio JD, Bittman R. Equilibrium binding of amphotericin B and its methyl ester and borate complex to sterols. Biochim Biophys Acta. 1982;685(2):219-224. doi:10.1016/0005-2736(82)90103-1

23. Shimizu K, Osada M, Takemoto K, Yamamoto Y, Asai T, Oku N. Temperature-dependent transfer of amphotericin B from liposomal membrane of AmBisome to fungal cell membrane. J Control Release. 2010;141(2):208-215. doi:10.1016/j.jconrel.2009.09.007

24. Takemoto K, Yamamoto Y, Ueda Y, Sumita Y, Yoshida K, Niki Y. Comparative study on the efficacy of AmBisome and Fungizone in a mouse model of pulmonary aspergillosis. J Antimicrob Chemother. 2006;57(4):724-731. 
25. Al Nakeeb Z, Petraitis V, Goodwin J, Petraitiene R, Walsh TJ, Hope WW. Pharmacodynamics of Amphotericin B deoxycholate, amphotericin B lipid complex and liposomal amphotericin B against aspergillus fumigatus. Antimicrob Agents Chemother. 2015;59(5):2735-2745. doi:10.1128/AAC.04723-14

26. Bellmann R. Clinical pharmacokinetics of systemically administered antimycotics. Curr Clin Pharmacol. 2007;2(1):37-58.

27. Bekersky I, Fielding RM, Dressler DE, Lee JW, Buell DN, Walsh TJ. Pharmacokinetics, excretion, and mass balance of liposomal amphotericin B (AmBisome) and amphotericin B deoxycholate in humans. Antimicrob Agents Chemother. 2002;46(3):828-833. doi:10.1128/ AAC.46.3.828-833.2002

28. Walsh TJ, Yeldandi V, McEvoy M, et al. Safety, tolerance, and pharmacokinetics of a small unilamellar liposomal formulation of amphotericin B (AmBisome) in neutropenic patients. Antimicrob Agents Chemother. 1998;42(9):2391-2398.

29. Bekersky I, Fielding RM, Dressler DE, et al. Plasma protein binding of amphotericin B and pharmacokinetics of bound versus unbound amphotericin B after administration of intravenous liposomal amphotericin B (AmBisome) and amphotericin B deoxycholate. Antimicrob Agents Chemother. 2002;46(3):834-840.

30. Vogelsinger H, Weiler S, Djanani A, et al. Amphotericin B tissue distribution in autopsy material after treatment with liposomal amphotericin B and amphotericin B colloidal dispersion. J Antimicrob Chemother. 2006;57(6):1153-1160. doi:10.1093/jac/ dk1141

31. Bekersky I, Fielding RM, Dressler DE, Lee JW, Buell DN, Walsh TJ. Plasma protein binding of amphotericin B and pharmacokinetics of bound versus unbound amphotericin B after administration of intravenous liposomal amphotericin B (AmBisome) and amphotericin B deoxycholate. Antimicrob Agents Chemother. 2002;46(3):834-840. doi:10.1128/AAC.46.3.834-840.2002

32. Lee JW, Amantea MA, Francis PA, et al. Pharmacokinetics and safety of a unilamellar liposomal formulation of amphotericin B (AmBisome) in rabbits. Antimicrob Agents Chemother. 1994;38 (4):713-718.

33. Bekersky I, Boswell GW, Hiles R, Fielding RM, Buell D, Walsh TJ. Safety and toxicokinetics of intravenous liposomal amphotericin B (AmBisome) in beagle dogs. Pharm Res. 1999;16(11):1694-1701.

34. Mistro S, Maciel I, de Menezes RG, Maia ZP, Schooley RT, Badaró R. Does lipid emulsion reduce amphotericin B nephrotoxicity? A systematic review and meta-analysis. Clin Infect Dis. 2012;54(12):1774-1777. doi:10.1093/cid/cis290

35. Wasan KM, Morton RE, Rosenblum MG, Lopez-Berestein G Decreased toxicity of liposomal amphotericin B due to association of amphotericin B with high-density lipoproteins: role of lipid transfer protein. J Pharm Sci. 1994;83(7):1006-1010. doi:10.1002/ jps. 2600830716

36. Bekersky I, Boswell GW, Hiles R, Fielding RM, Buell D, Walsh TJ. Safety, toxicokinetics and tissue distribution of long-term intravenous liposomal amphotericin B (AmBisome): a 91-day study in rats. Pharm Res. 2000;17(12):1494-1502. doi:10.1023/A:1007605024942

37. Sau K, Mambula SS, Latz E, Henneke P, Golenbock DT, Levitz SM The antifungal drug amphotericin B promotes inflammatory cytokine release by a Toll-like receptor- and CD14-dependent mechanism. J Biol Chem. 2003;278(39):37561-37568.

38. Wade RL, Chaudhari P, Natoli JL, Taylor RJ, Nathanson BH, Horn DL. Nephrotoxicity and other adverse events among inpatients receiving liposomal amphotericin B or amphotericin B lipid complex. Diagn Microbiol Infect Dis. 2013;76(3):361-367.

39. Roden MM, Nelson LD, Knudsen TA, et al. Triad of acute infusion-related reactions associated with liposomal amphotericin B: analysis of clinical and epidemiological characteristics. Clin Infect Dis. 2003;36(10):1213-1220.
40. Szebeni J, Baranyi L, Savay S, et al. Liposome-induced pulmonary hypertension: properties and mechanism of a complement-mediated pseudoallergic reaction. Am J Physiol Heart Circ Physiol. 2000;279 (3):H1319-H1328

41. Kolve H, Ahlke E, Fegeler W, Ritter J, Jürgens H, Groll AH. Safety, tolerance and outcome of treatment with liposomal amphotericin B in paediatric patients with cancer or undergoing haematopoietic stem cell transplantation. J Antimicrob Chemother. 2009;64(2):383-387.

42. Patel GP, Crank CW, Leikin JB. An evaluation of hepatotoxicity and nephrotoxicity of liposomal amphotericin B (L-AMB). J Med Toxicol. 2011;7(1):12-15.

43. Fischer MA, Winkelmayer WC, Rubin RH, Avorn J. The hepatotoxicity of antifungal medications in bone marrow transplant recipients. Clin Infect Dis. 2005;41(3):301-307.

44. Chamilos G, Luna M, Lewis RE, Chemaly R, Raad II, Kontoyiannis DP. Effects of liposomal amphotericin B versus an amphotericin B lipid complex on liver histopathology in patients with hematologic malignancies and invasive fungal infections: a retrospective, nonrandomized autopsy study. Clin Ther. 2007;29(9):1980-1986.

45. Reithinger R, Dujardin JC, Louzir H, et al. Cutaneous leishmaniasis. Pediatr Infect Dis J. 2007;7:581-596.

46. Hervás JA, Martín-Santiago A, Hervás D, et al. Old world Leishmania infantum cutaneous leishmaniasis unresponsive to liposomal amphotericin B treated with topical imiquimod. Pediatr Infect Dis J. 2012;31(1):97-100.

47. Berman JD, Badaro R, Thakur CP, et al. Efficacy and safety of liposomal amphotericin B (ambisome) for visceral leishmaniasis in endemic developing countries. Bull World Health Organ. 1998;76:25-32.

48. Croft SL, Olliaro P. Leishmaniasis chemotherapy-challenges and opportunities. Clin Microbiol Infect. 2011;17(10):1478-1483.

49. Alvar J, Croft S, Olliaro P. Chemotherapy in the treatment and control of leishmaniasis. Adv Parasitol. 2006;61:223-274.

50. Garnier T, Croft SL. Topical treatment for cutaneous leishmaniasis. Curr Opin Investig Drugs. 2002;3:538-544.

51. El-On J, Halevy S, Grunwald MH, Weinrauch L. Topical treatment of old world cutaneous leishmaniasis caused by Leishmania major: a double- blind control study. J Am Acad Dermatol. 1992;27:227-231.

52. Ben Salah A, Buffet PA, Morizot G, et al. Wr279,396, a third generation aminoglycoside ointment for the treatment of Leishmania major cutaneous leishmaniasis: a phase 2, randomized, double blind, placebo controlled study. PLoS Negl Trop Dis. 2009;3:e432.

53. Asilian A, Jalayer T, Nilforooshzadeh $\mathrm{M}$, et al. Treatment of cutaneous leishmaniasis with aminosidine(paromomycin) ointment: double-blind, randomized trial in the Islamic Republic of Iran. Bull World Health Organ. 2003;81:353-359.

54. Soto J, Arana BA, Toledo J, et al. Miltefosine for new world cutaneous leishmaniasis. Clin Infect Dis. 2004;38:1266-1272.

55. Yardley V, Croft SL, Doncker SD, et al. The sensitivity of clinical isolates of leishmania from Peru and Nepal to miltefosine. Am J Trop Med Hyg. 2005;73:272-275.

56. Wortmann G, Zapor M, Ressner R, et al. Lipsosomal amphotericin B for treatment of cutaneous leishmaniasis. Am J Trop Med Hyg. 2010;83:1028-1033

57. Gonzalez U, Pinart M, Reveiz L, Alvar J. Interventions for old world cutaneous leishmaniasis. Cochrane Database Syst Rev. 2008;8(4): CD005067.

58. Emad M, Hayati F, Fallahzadeh MK, Namazi MR. Superior efficacy of oral fluconazole $400 \mathrm{mg}$ daily versus oral fluconazole $200 \mathrm{mg}$ daily in the treatment of cutaneous Leishmania major infection: a randomized clinical trial. J Am Acad Dermatol. 2011;64:606-608.

59. Gonzalez U, Pinart M, Rengifo-Pardo M, Macaya A, Alvar J, Tweed JA. Interventions for American cutaneous and mucocutaneous leishmaniasis. Cochrane Database Syst Rev. 2009;15(2):CD004834. 
60. Miranda-Verastegui C, Tulliano G, Gyorkos TW, et al. First-line therapy for human cutaneous leishmaniasis in Peru using the TLR7 agonist imiquimod in combination with pentavalent antimony. PLoS Negl Trop Dis. 2009;3:e491.

61. Convit J, Ulrich M, Zerpa O, et al. Immunotherapy of American cutaneous leishmaniasis in Venezuela during the period 1990-99. Trans R Soc Trop Med Hyg. 2003;97:469-472.

62. Guery R, Henry B, Martin-Blondel G, et al. Liposomal amphotericin $\mathrm{B}$ in travelers with cutaneous and muco-cutaneous leishmaniasis: not a panacea. PLoS Negl Trop Dis. 2017;11(11):e0006094.

63. Layegh P, Rajabi O, Jafari MR, et al. Efficacy of topical liposomal amphotericin $\mathrm{B}$ versus intralesional meglumine antimoniate (Glucantime) in the treatment of cutaneous leishmaniasis. J Parasitol Res. 2011;2011:656523.

64. Motta JO, Sampaio RN. A pilot study comparing low-dose liposomal amphotericin B with N-methyl glucamine for the treatment of American cutaneous leishmaniasis. J Eur Acad Dermatol Venereol. 2012;26(3):331-335.

65. Hamzavi SS, Sanaei Dashti A, Kadivar MR, Pouladfar G, Pourabbas B. Successful treatment of disseminated cutaneous leishmaniasis with liposomal amphotericin B and miltefosine in an eight-year-old girl. Pediatr Infect Dis J. 2018;37(3):275-277.

66. Islam S. Rapidly progressing facial leishmaniasis: effective treatment with liposomal amphotericin B and a review of the management of old world cutaneous leishmaniasis. Paediatr Int Child Health. 2018;38(2):158-161.
67. Cunha MA, Leão AC, de Cassia Soler R, Lindoso JA. Efficacy and safety of liposomal amphotericin B for the treatment of mucosal leishmaniasis from the new world: a retrospective study. Am J Trop Med Hyg. 2015;93(6):1214-1218.

68. Butsch F, Faulde M, Debus A, Bogdan C, von Stebut E. Two cases of successful treatment of multilesional cutaneous leishmaniasis with liposomal amphotericin B. JDDG. J Dtsch Dermatol Ges. 2013;11 (1):83-85.

69. Zanger P, Kötter I, Raible A, Gelanew T, Schönian G, Kremsner PG. Successful treatment of cutaneous leishmaniasis caused by Leishmania aethiopica with liposomal amphothericin b in an immunocompromised traveler returning from eritrea. Am J Trop Med Hyg. 2011;84(5):692-694.

70. Ono M, Takahashi K, Taira K, Uezato H, Takamura S, Izaki S. Cutaneous leishmaniasis in a Japanese returnee from West Africa successfully treated with liposomal amphotericin B. J Dermatol. 2011;38(11):1062-1065.

71. Solomon M, Pavlotsky F, Leshem E, Ephros M, Trau H, Schwartz E. Liposomal amphotericin B treatment of cutaneous leishmaniasis due to Leishmania tropica. J Eur Acad Dermatol Venereol. 2011;25 (8):973-977.

72. Solomon M, Pavlotzky F, Barzilai A, Schwartz E. Liposomal amphotericin $\mathrm{B}$ in comparison to sodium stibogluconate for Leishmania braziliensis cutaneous leishmaniasis in travelers. $J$ Am Acad Dermatol. 2013;68(2):284-289.
Research and Reports in Tropical Medicine

\section{Publish your work in this journal}

Research and Reports in Tropical Medicine is an international, peerreviewed, open access journal publishing original research, case reports, editorials, reviews and commentaries on all areas of tropical medicine, including: Diseases and medicine in tropical regions; Entomology; Epidemiology; Health economics issues; Infectious disease; Laboratory science and new technology in tropical medicine;
Parasitology; Public health medicine/health care policy in tropical regions; and Microbiology. The manuscript management system is completely online and includes a very quick and fair peer-review system. Visit http://www.dovepress.com/testimonials.php to read real quotes from published authors. 